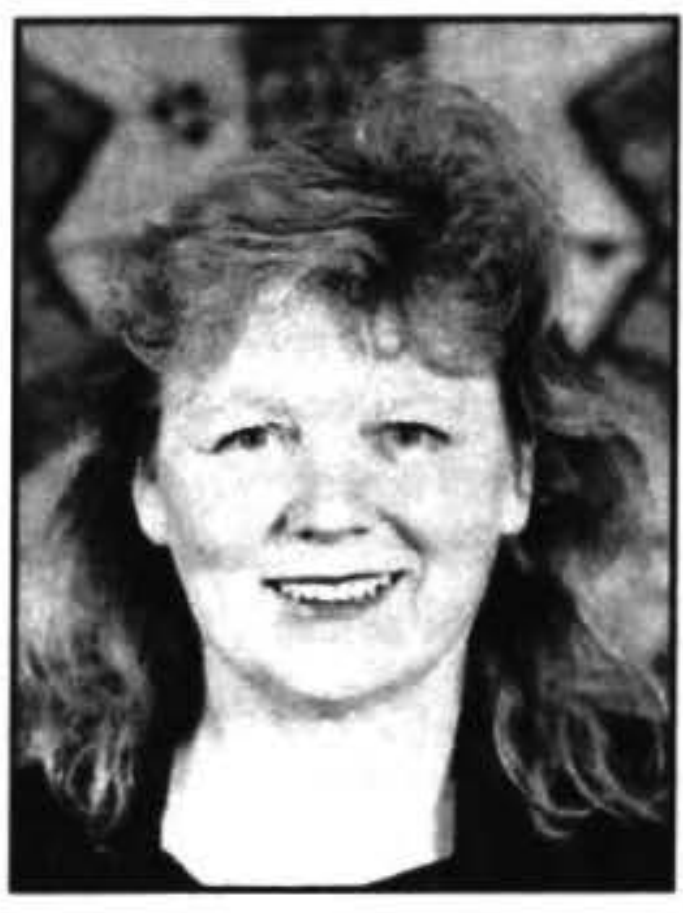

\title{
EXPERIENCES OF ACADEMICS OF WORKLOAD AND RESPONSES BY UNIONS AND MANAGEMENT
}

\author{
Jill Ovens \\ Senior Lecturer (Journalism) \\ Auckland University of Technology and \\ National President \\ Association of Staff in Tertiary Education
}

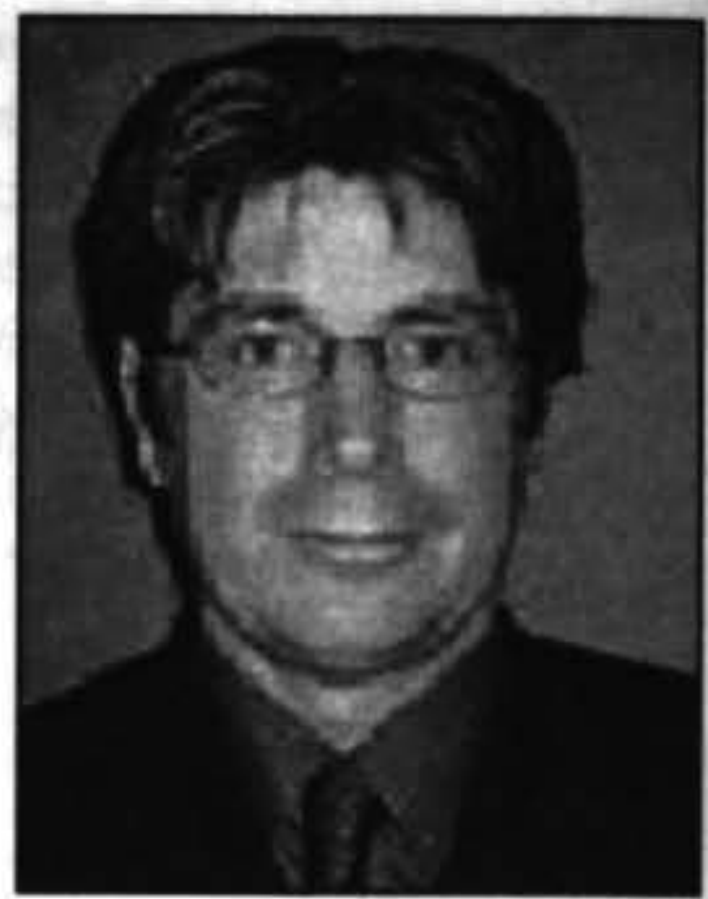

\section{Derek McCormack}

\author{
Deputy Vice-Chancellor for Administration \\ Auckland University of Technology
}

\begin{abstract}
Academic staff in tertiary institutions say they are overworked and undervalued. Recent changes in education provision and funding have meant that providing safe, equitable and reasonable workloads is an increasingly difficult management task. The paper arises from a joint union/management working party that surveyed historical and current contexts, including approaches used to assess and allocate academic work in a variety of tertiary institutions. We surveved regulatory provisions contained in tertiary education collective agreements and found there was no single solution, given the diversity of the sector. Nevertheless we have identified workload models that provide a framework for discussion and negotiation between unions and management in the tertiary education sector.
\end{abstract}

Keywords: Tertiary institutions, academic, workloads

Academic work in tertiary institutions involves a complex mix of activities and responsibilities with a number of characteristics that distinguishes it from other occupations. As Sadler (2000: 18) says:

\begin{abstract}
We teach students, we do research, we help with the administrative overheads in our departments and we contribute to the collegiate governance of our institutions. We also perform significant specialist services for the wider professional world and the public at large.
\end{abstract}

Many of these elements are unquantifiable and this forces reliance on subjective assessments by those whose task it is to allocate, manage and control workloads. Philp (1993) notes there is no widely acceptable and consistent convention to allocating teaching loads within academic departments and yet the allocation is often hotly contested.

It is perhaps surprising that there is little evidence that the issue itself has ever been accorded the scrutiny that academics everywhere tend to give to issues far less attached to the quality of their daily working lives, he says.
University academics have traditionally enjoyed a great deal of autonomy and self-regulation in the distribution of their work. Successive cuts in Government funding during the 1990s have affected the universities' ability to resource expected working conditions, and forced increasing reliance on the characteristic open-endedness of academic work. By the late 1990s, workloads emerged as a major concern in university employment relations, with workload working parties being established at Massey University and Waikato University.

In polytechnics and colleges of education, on the other hand, contractual provisions have been used historically to control the distribution of workload and thus most discussion of the matter has occurred within the context of industrial negotiations. This has proven to be increasingly fraught as the sector has faced a period of rapid change and increasing complexity. Our paper arises from the report of a joint working party convened in 1996 by the Association of Staff in Tertiary Education (ASTE) and the CEOs of several polytechnics to consider the management of academic workload. (Polytechnic, 1996)

Prompted by that work, we survey and discuss the factors impacting on workload of academic staff in the last two decades. We consider attempts made to control and dis- 
tribute workload in tertiary institutions, including regulatory provisions through our survey of all New Zealand tertiary sector collective agreements or contracts. An historical survey of the development of workload protections in polytechnics is given as an illustration of the approach to workload solutions. To take a cross-sectoral view, we have incorporated more recent insights from or about the university sector. The task of developing one workload management model that would function across the tertiary education sector continues to elude those who seek it. Accordingly, we present a framework for dialogue by interested parties, including those involved in negotiations about academic workload within the context of tertiary sector industrial relations.

\section{Historical Context}

The recent rise in New Zealand of multi-sectoral universities, through mergers of universities with colleges of education (at the University of Waikato and at Massey University) and polytechnics (Wellington Polytechnic with Massey University), brought different cultures into direct contact with each other. As well, the conversion of Auckland Institute of Technology to a university (as AUT) has created an impetus for workload to be addressed as sectoral disparities are highlighted. While academics throughout the tertiary system share a widespread concern about burgeoning workloads, their approach to solving the problem is very different and this reflects their different histories. There is a need for academics and management to understand the origins of workload controls in various parts of the tertiary sector before there can be a consensus as to what the problem is and what to do about it.

University academic salaries were traditionally negotiated through the Higher Salaries Commission and thus salaries and conditions were not subject to industrial awards. Tarling (2000: 108) argues that academics were constrained from seeking improvements to their salaries and conditions by a sense of obligation to their students and the old HSC arrangement had concealed their lack of industrial power (or will to exercise it). The labour relations reforms of the fourth Labour Government forced the Association of University Staff (AUS) to act as a union, which was confirmed by the Employment Contracts Act 1992. For the first time, conditions of university academics were codified in enterprise contracts, and in 1993, academic workloads became part of the AUS bargaining strategy.

Regulation of academic workloads by university collective employment contracts or agreements remains minimalist. (Table 1) It is significant that it was at those universities where there were mergers with colleges of education (at Massey and Waikato) that the first working parties with representatives of union and management were established to look at processes to regulate academic workload.

The polytechnic sector had quite a different history characterised by persistent interest in workload matters by staff and managers. Polytechnics (then "technical institutes") developed out of the secondary sector in the 1960s, and tutors' workloads were based on those of their high school counterparts. Whereas schools operated on limited hours of opening, which helped to constrain hours of work, polytechnics were more flexible and consequently, hours of work were codified, both for teaching (class contact hours) and for requirements to be on site (duty hours). The Technical Institutes Regulations of 1969 and the Technical Institutes Determination of the Government Services Tribunal substantially confirmed schools-based workloads for the new sector by setting down a maximum of 960 class contact hours and up to 1360 duty hours for a polytechnic teacher in a year. The flexibility of the polytechnic operation meant that workloads were variable throughout the year, and polytechnic tutors and managers regularly recorded class contact and duty hours to ensure that limits were not breached.

The Association of Technical Institute Teachers (ATTI) conducted a workload campaign in the late 1970s and in 1981, the Government amended regulations to drop the annual class contact hour maximum to 800 a year. In 1988 , the Association of Polytechnic Tutors (NZAPT, formerly ATTI) commissioned O'Neill to conduct a workload survey. (O'Neill, 1990) The survey responded to contention on the part of management that the 800 hours maximum was unrealistic and too rigid. Tutors were concerned that the 800 contact hours was being treated as the target rather than the maximum and was not, therefore, constraining total hours of work to acceptable limits. O'Neill found that polytechnic tutors reported an average of 18 contact hours a week (about 600-650 hours a year), but that the total diaried work averaged 44.5 hours a week during term time.

O'Neill also found that the character of their work had been changing, with tutors reporting a growth in administration, preparation and assessment conducted out of class time. An increasingly broad range of vocational education was being offered by polytechnics with the introduction of professional programmes, such as those for nursing, and of transition education and training associated with the rise of youth unemployment that accompanied economic restructuring. There was also a shift away from external examinations towards internal assessment, and locally developed programmes gave rise to new curriculum development work previously dealt with by national agencies such as the Trades Certification Board and the Authority for Advanced Vocational Awards. (Polytechnic, 1996: 7)

Other factors kept the issues of workload alive. Accreditation requirements for providers offering national certificates, set in consultation with the relevant industry, included contact teaching maxima to ensure rigorous assessment. For example, the National Certificate in Business Studies (NCB) required that no teacher should be assigned more than 16 hours contact teaching a week. This produced a significant downward pressure on teaching 


\title{
Table 1. Academic Workload Regulation by Collective Agreement or Collective Employment Agreement in New Zealand Universities
}

Agreement or CEC

Victoria University

Expired August 312000

Auckland University

Expires January 312002

\author{
Features
}

No specific provisions except attendance requirement, ie scheduled teaching, meetings, examinations, student and research consultation.

Principles of workload include: HOD and departmental staff to determine workload norms in allocation of teaching, research and service; 4 weeks annual leave; fair and equitable workload to be mutually agreed by HOD and individual staff; summer school requires adjustment of time available throughout year for research and scholarship; preferences re evening, weekend and summer classes to take account of family and personal needs; workload considerations of offcampus teaching include admin, transport issues; may be salary adjustment for extraordinary workload.

Lincoln University

Expires June 302001

anterbury University

Expires December 312000

Waikato University

Expires September 112001
Hours of work such as are reasonably required to fulfil duties; not normally outside $7 \mathrm{am}$ to $9 \mathrm{pm}$ or for more than 5 consecutive days a week; good employer requirement; refers to work and family policy and academic staff work allocation guidelines to be reviewed in 2000 .

Hours of work such as are reasonably required to fulfil duties; to be worked at such time and on such days as Employer reasonably requires; consideration to be given to needs of employee and current practice; part-timers' requirements to be proportional to fulltime duties.

Statement of recognition of need for fair, safe, healthy and equitable workloads while acknowledging cyclical variation of responsibilities and operational needs; transparent measurement and allocation processes to have regard for overall workload levels and spread across time; consistency across different academic groups; workloads to be developed in November for following year and finalised when enrolments known; factors to be considered include particular responsibilities and job description including but not limited to teaching, supervision, assessment, examining, scholarship, research, administration, external/community activities; concerns to be raised with chairperson to be resolved within the department or unit; if unresolved, to go to Dean.

Massey University

Expires October 12001

University to develop a workloads policy in consultation with unions that are party to the Agreement; policy to acknowledge importance of setting workloads that are transparent, equitable, flexible and that promote the well being and safety of staff.

Otago University

Expires May 312001

Auckland University of

Technology

Expires March 12001
Hours of work such as are reasonably required to fulfil duties; to be worked at such time and on such days as Employer reasonably requires; consideration to be given to needs of employee and current practice; part-timers' requirements to be proportional to fulltime duties.

Agreement contains standard polytechnic regulation (see Table 2), but two policies are appended that modify; the first creates two pathways for academics teaching and research; the relative emphasis on each activity is reflected in the titles; the second policy is a workloads model that weights total contact hours using bands that describe staff (a) mainly engaged in research $(0-240$ TTH), (b) post-grad/undergrad mix (51-300), (c) undergrad (301-450), (d) certificate/diploma (451-600), (e) workshop-based (601-825); these bands are defined in terms of NZQA levels and reflect the range of programmes offered by the university; staff commonly teach across one or more of these so TTH is weighted accordingly; policy also contains principles (eg safe, reasonable, equitable, complexity constrained, organisation efficient, all factors to be taken into account) and principles underlying allocation (transparent, consultative, planned); policy contains a dispute resolution process and stress management guidelines; the policy is currently being reviewed. 
hours in the sector.

At the same time, the emergence of private training providers, under the ACCESS training scheme, was a counter-balancing pressure tending to increase polytechnic teaching loads. PTEs competed with the public sector for funding under this scheme, but the PTE teaching loads were higher and teaching costs lower than those of the polytechnics.

The Education Amendment Act 1990 prompted comparisons of polytechnic teaching in another direction by opening up the possibility of non-university degrees. Average polytechnic teaching hours were higher than those in either universities or colleges of education (where degrees were also being offered) and if a research culture was to be encouraged, teaching hours needed to come down for those polytechnic tutors now teaching on degrees. This was confirmed by approval arrangements of the new NZQA (New Zealand Qualifications Authority), which emphasised academic staff research.

The bulk funding arrangements of the Education Amendment Act theoretically allowed for some redistribution of resources within polytechnics to provide for lower teaching loads on particular programmes. However, successive reductions in Government funding throughout the 1990 s, accelerated in response to the so-called "Asian Crisis" in 1997, (MOE, 2000: 66) meant that it was difficult to hold down workloads of those teaching on degrees without increasing others' workloads. Hardie-Boys (1996: 19) found that trades tutors were most likely to report an overall increase in their workload over recent years (93\%). $\mathrm{He}$ also found a wide spread in reported class contact hours, from 20.3 hours a week for trades tutors down to 13.5 for colleges of education staff, reflecting the greater proportion of their teaching on degree programmes. (Hardie-Boys, 1996: 14) The polytechnic average was 18.1 contact hours a week, confirming O'Neill's earlier result, but the total work hours reported during term time had increased to more than 48 hours. (Hardie-Boys, 1996: 13) Thus workloads were increasing, while class contact remained the same or decreased.

As well, the linking of funding to equivalent fulltime students (EFTS) removed the financial incentive for teacherintensive approaches common in polytechnics and colleges of education. This had been reflected in lower staff/ student ratios in polytechnics than in universities, a difference that has steadily disappeared. (MOE, 2000: 2122)

Throughout the period of change, the relevant industrial awards and collective employment contracts for polytechnic academic staff maintained the class contact hours as a workload limit, though the limit was raised from $800 \mathrm{TTH}$ to $825 \mathrm{TTH}$ in most polytechnic CECs and as high as 850 TTH in some. (See Table 2 at end of the paper) A general requirement was added in 1992 that employers were to ensure equitable, reasonable and safe workloads. As an outcome of negotiations involving a consortium of fourteen polytechnics in 1995, the joint ASTE/management Workloads Working Party met during 1996 and their report formed the basis of ASTE claims in the subsequent round of collective contract negotiations in 1998. Again, it proved difficult to reach agreement in the context of negotiations and the parties agreed to a policy development process involving wide consultation. Five years later, some of the polytechnics involved have yet to complete that process.

\section{Hours of Work and Workload}

Boyd and Wylie (1994) found that the average reported working week for fulltime academic staff in New Zealand universities was 53 hours. Hardie-Boys' (1996: 13) found an average of 56 hours in colleges of education. These results were consistent with international studies of workload in tertiary institutions. An overview of US faculty workload found 55 hours a week to be remarkably consistent. (Wergin: 1994) Kinman's UK study (1998) found $40 \%$ of academics working 51 hours a week or more. Australian academic staff reported an average of nearly 53 hours. (McConville \& Allport, 2000)

Although university staff estimates of the number of hours they spent working each week were much the same in 1998 as in 1994, (Chalmers, 1998: 3) at least three-quarters of respondents thought their workload had increased. Chalmers also reported that most university staff were unhappy with the balance of their current workload. Nearly a quarter of academic staff reported they would like to spend more time on research and less on teaching, suggesting that total work estimates may not correlate with the sense of acceptability of workload as the mix of responsibilities change.

This reflects an Australian study (McInnes, 2000) that tracked changes in workload, stress and job satisfaction between 1993 and 1999 and found a high level of dissatisfaction in relation to salaries and working conditions, in particular declining opportunities to pursue academic interests. The report concluded that:

We are perhaps at a critical point for the
academic profession where the amount of
hours worked, and the diffusion and frag-
mentation of tasks seriously threatens the
quality of both research and teaching.

\section{Tertiary Education Trends and Impact on Academic Work}

A number of readily identifiable trends have tended to increase academic workloads across the tertiary sector in New Zealand. There was a large increase in the number of students enrolled in tertiary institutions in the late $1980 \mathrm{~s}$ and early 1990s, which leveled off in the last two years. (MOE, 2000: 29) The increase in student numbers was sharply felt by academic staff (Chalmers, 1998: 32; 
Hardie-Boys, 1996: 21) as it was not matched by a relative increase in their numbers. Between 1995 and 1999, student numbers rose by $10 \%$ across the sector, while the number of teaching and academic staff increased by just $5 \%$ over the same period. (MOE, 2000: 21 ) Not only were academic staff working with more students, but the student body was becoming increasingly diverse as more school leavers and adults took up tertiary education, and as international enrolments burgeoned.

Staff were also expected to be more adaptable. Professions such as teaching, accountancy and nursing have become graduate professions. Thus academic staff in these disciplines have had to upgrade their qualifications and at the same time, have been expected to produce research to support the new degree programmes. As well, there has been a shift from national examinations to competencybased assessments associated with the National Qualifications Framework. Increasingly complex quality assurance requirements of CUAP and NZQA have accompanied growth in development of new courses. It is no wonder therefore that new or expanded job requirements were the number one reason given by staff to explain the increase in their workloads. (Hardie-Boys, 1996: 26) According to Chalmers, some of these increased demands on staff may reflect the growing use of information and communications technology. As well, there has been an increase in administrative workload associated with devolution, restructuring and redundancies. (Chalmers, 1998: 3)

The rapid pace of change and increases in workload during the 1990s had a profound effect on the private lives of academic staff. About half the respondents to the HardieBoys' study reported that workload changes had produced a deterioration of their physical or emotional health. More than half said they had taken less leave as a result of in- creased workloads. (Hardie-Boys, 1996: 23) Ovens (1995) found that while contractual provisions for leave were adequate, polytechnic staff had been unable to take such leave because of workload pressures. University staff (Massey, 2000) also reported difficulty in taking breaks, and claimed that increased workloads were compromising the balance between their work and private lives.

Riggs (1994) found that women academics were experiencing the education reforms of the 1990s differently than men. While women and men reported similar hours of classroom teaching, the women spent more time in areas such as student interaction and class preparation. They also spent more time studying for qualifications. HardieBoys (1996: 35) found women to be significantly more likely than their male colleagues to mention upskilling and attaining qualifications as a cause of stress. They were also more likely to cite research, writing and publishing in this regard. Chalmers (1998: 45) reported that women academics were more likely to mention lack of job security, university redundancies, availability of relief staffing, and IT support as sources of stress in their jobs.

\section{Health and Safety: An Emerging Workload Issue}

While excessive workloads have an obvious impact on the quality of education, managers of tertiary institutions also need to consider their responsibilities with respect to health and safety. The recent $\$ 900,000$ settlement in a case relating overwork to stress is a salutary reminder of the employer's duty to provide, so far as practicable, a working environment that is safe for employees and without risks to their health. (Gilbert vs Attorney-General, 2000 ) One difficulty is that hours of work may become

\section{Figure 1. Changes in Responsibility for Workload as Situations take on Professional or Managerial Orientations.}

MANAGEMENT

EXTERNAL PRESSURES

$\rightarrow \quad$ Research output

$\rightarrow \quad$ Limited funding and resources

$\rightarrow$ Quick response times

$\rightarrow$ Compliance with funding agencies and NZQA

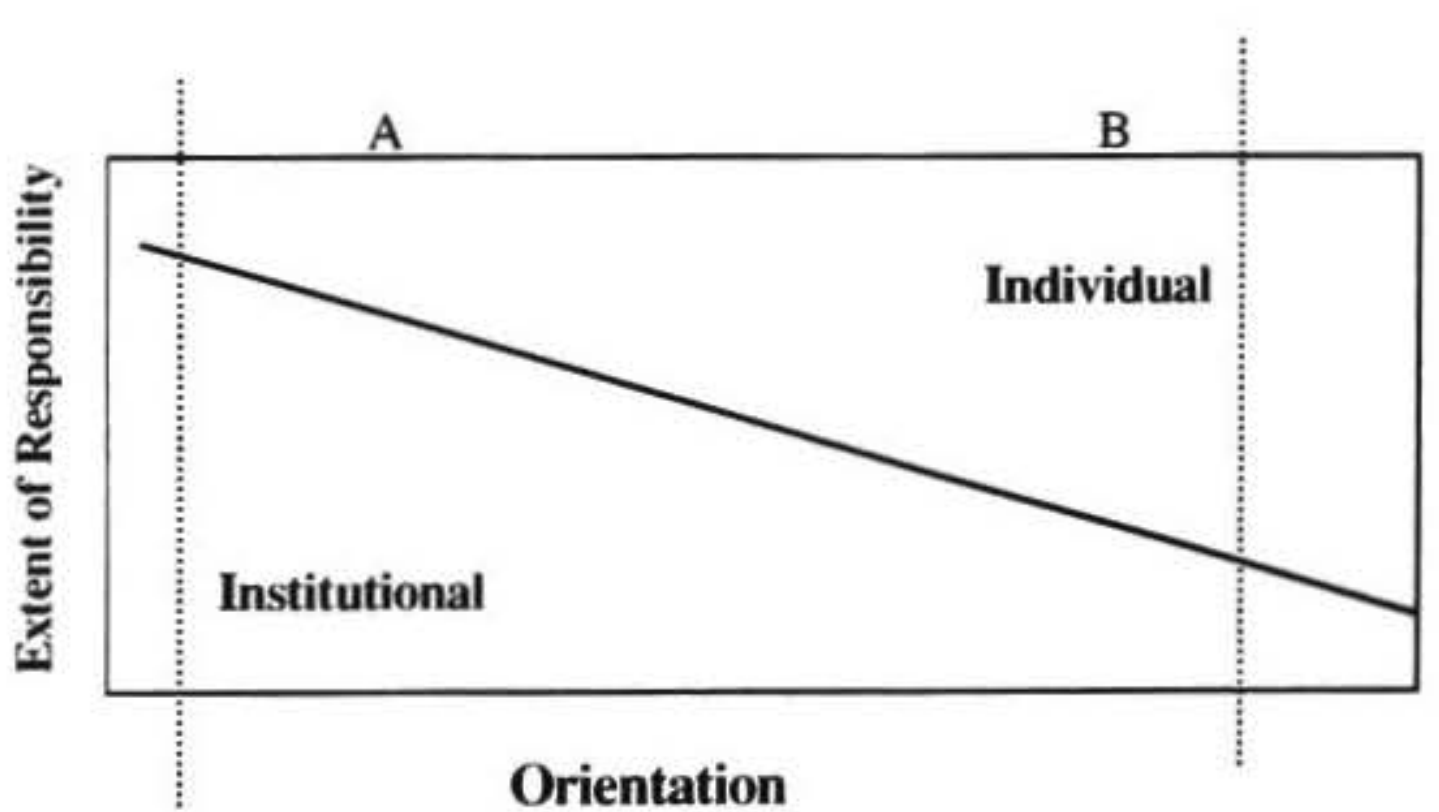

PROFESSIONAL

EXTERNAL PRESSURES

Managerial 
excessive before any attempt is made to address the problem. Also, there is a requirement on workers to identify hazards in the workplace, (HSE Act 1992, S19) so that in the case of excessive workloads, the staff member must be able to demonstrate that the matter has been brought to management's attention. This is problematic where there are no review processes in place and a lack of transparency about how workloads are allocated or measured.

\section{The Dynamics of Workload Responsibility}

The model represented by Figure 1 encapsulates the tensions inherent in the management of academic workload. Movement along the horizontal axis to the right implies greater professional orientation with a higher professional responsibility for setting the workload. Movement to the left reflects a managerial orientation with greater institutional responsibility for managing workloads.

While there is an employer/employee relationship, academic staff are professionals with statutory protection of their academic freedom and operate with a high degree of autonomy. This implies that to some extent, academic staff must be responsible for the level and control of their own workload. On the other hand, managers allocate resources that determine the level of staffing in any given faculty or school. Even if academics were free to distribute their work using a collaborative model and did so equitably, this would not ensure that workloads were reasonable or safe.

The orientation varies across the tertiary sector. For example, in trades education most of the teaching is face-toface. Assessment is competency-based and occurs within the classroom or workshop. Thus contact hours are high and need to be constrained in a prescriptive manner. Universities are associated with an autonomous approach, which is reflected in the lack of regulation contained in university collectives. Multi-sectoral universities provide a particular challenge as they attempt to meet the needs of diverse groups.

External pressures may force a particular orientation, with a consequential adjustment to the division of responsibility for workload. Pressures on management include the allocation of diminishing resources (especially in smaller regional polytechnics) and requirements to increase research outputs (for example, in polytechnics seeking university status, or in colleges or polytechnics merging into universities). External pressures on academic staff include the need to access resources, which may lead to teaching and research being directed into more "profitable" areas (for example, revenue-generating activities or corporatefunded research). To be broadly acceptable, workload models must be capable of aligning the professional interests associated with independent teaching and research, and the managerial interest in the goals or mission of the institution.

\section{Approaches to Allocating Academic Staff Workloads}

Our survey identified two types of approaches to allocating academic staff workloads. The first were those for which justifiability is the key issue - implying an orientation towards measurement and emphasising the managerial role. We have classified these as "quantitative" approaches. The second type are those for which acceptability is the key issue - implying an orientation towards process and emphasising the professional role. We have classified these as "process" approaches.

\section{Quantitative Approaches}

\section{Contact Teaching Hours}

The assumption of this system is that the major workload driver is timetabled teaching activity and if this is controlled, workload will be too. This measure works well where timetabled teaching is the main activity. Until recently, this was the most commonly used method in the polytechnic sector. (Table 2) The advantages are simplicity, visibility and measurability. However, the measure ignores the inconsistency of demands associated with different types of teaching, for example complexity of assessment and preparation. It fails to protect workload where there are other expectations in addition to teaching, such as research.

\section{Weighted Contact Hours or Contact Teaching Bands}

In this system, now widely used in the polytechnic sector, an adjustment is made either to each hour of contact teaching, or to the maximum annual totals (TTH), to recognise that different teaching activities require varying amounts of preparation and follow-up. Workload is managed within a maximum number of adjusted hours (for example, in bands designed to accommodate degree teaching with an expectation of research activity, certificate or diploma teaching, or workshop-based teaching). (See AUT, Table 1) The measure requires broad agreement on the weighting of different activities.

\section{Workload Units}

This system, used in some colleges of education, (Table 2) assigns a unit value to specified tasks such as contact teaching, membership of academic committees, or curriculum development. Hours of teaching may be assigned different values dependent on the number of students, the number of times the teaching is repeated, and the level of the teaching. Workload is constrained within a maximum number of units, typically within a year. Philip's system, based on hour units (HUs) and normal teaching load (DTL), is a version of this. Sullivan used a modified version of this as chair of the Victoria University Education Department (Sullivan, 1997). These systems clarify the extent of a full workload, giving emphasis to activities other than up-front teaching. However, while the systems appear to be objectively measurable, the assignment of 
workload values to the various elements is subjective. Thus they are open to challenge.

\section{Actual Hours Worked}

The total hours worked on all activities are diaried and regularly monitored. The system is widely used in professions such as law and accounting where paying clients demand a justification of work spent on their accounts. However, in an academic environment, the recording and monitoring of hours worked is problematic, both from a pragmatic and philosophic point of view (as students are not clients and the relationship is quite different). A version commonly used in universities is to break down the number of hours proportionally, for example, 33\% teaching, 33\% research and $33 \%$ administration/community service. (Sullivan, 1997: 37)

\section{Credit Hours}

In this system, widely used in US colleges and universities, the workload is based on the number of course credits. In the NZQA system, a credit equates to 10 student learning hours, so 60 credits would mean that the staff member was responsible for 600 student learning hours in the year. How these would be delivered would depend on the nature of the course, the requirements of the institution and the professional judgement of the staff member. The system takes into account the varieties of teaching styles and needs of different courses by relying on the output of credits, rather than the input of hours. It fails to take account of the number of students in each class, although it could be adjusted to do so.

\section{Other Outputs-based Systems}

Work could be allocated to teaching teams or individuals on the basis of projected student numbers (EFTS). Other measures could include research outputs or revenue earned. These systems would be well suited to the market-driven tertiary education system of the last decade. However, it is doubtful whether any of the above would enhance the delivery of quality education.

\section{Process Approaches}

\section{Individual Negotiation}

Staff plan their annual workload with the Head of Department using agreed guidelines. Or a team negotiates workloads co-operatively, which works well in a collegial environment where there is an equal power balance between participants. (Sullivan, 1997: 27) However, it could lead to exploitation where this is not the case (eg in a highly casualised department ).

\section{HOD Assignment}

In some cases, the HOD unilaterally assigns workload based on set guidelines. The main problem with this and the above processes, is transparency of the guidelines used. For example, the Massey University workloads group (2000: 7-8) received a number of descriptions from de- partments of guidelines used in the allocation of workloads, but these were not always known to staff. It was also clear that there was a considerable variation in individual workloads within a given department, despite the existence of guidelines.

\section{Workload Auction}

The system is similar to the workload units systems described above, but rather than unit values being arbitrarily assigned, the value of each unit is determined by auction among staff. A full workload is achieved by successfully bidding for, say, 1000 points of work in the auction. The HOD may put a "reserve" maximum number of points on the unit of work, which may be adjusted if the work fails to meet the reserve. The Polytechnic Workloads Working Party (1996: 41) included this as a creative way of achieving agreement about workload. It is unlikely to be widely applied.

\section{Conclusion}

Our survey of approaches to workload allocation highlighted problems in each of the systems used. This suggests that no single model will adequately address the diversity of the sector or the range of factors involved. One commentator suggests that work allocation is like a threelegged stool. (Keith Hargiss, MIT human resources manager, private communication) The legs of the stool are use of an open and clear process, sound underlying principles and appropriate quantitative measures. Take away one of the legs and the stool falls over.

Examples of underlying principles developed from the polytechnic and Massey University working parties are contained in Appendix I, and aspects of appropriate processes are in Appendix II.

\section{Future Research}

One suggested future area of research is the impact of eeducation on workload. The "virtual university" is being welcomed by policymakers as a panacea, both because of the potential to increase access to tertiary education for the disadvantaged, and also to do so cheaply. (Gladieux \& Swaill, 1999) But academic staff warn there are costs associated with the new technology, including the potential to increase workloads by requiring staff to be constantly available and by increasing the volume of communications. (ASTE, 2000: 7)

It would also be of interest to investigate the structure of resourcing systems and models used to allocate staffing to identify the degree of consistency with workload assessment systems. This would need to be considered at two levels: Government funding and institutional budgeting. 
References

ASTE Te Hau Takitini o Aotearoa (2000) Submission to the Tertiary Education Advisory Council. The Shape of the Sector. http://www.aste.ac.nz

Boyd, S. \& Wylie, C. (1994) Workload and Stress in New Zealand Universities. Wellington: New Zealand Council for Educational Research and the Association of University Staff.

Chalmers, A. (1998) Workload and Stress in New Zealand Universities. A Follow-up to the 1994 Study. Wellington: New Zealand Council for Educational Research and the Association of University Staff.

Gilbert vs Attorney-General in respect of the Chief Executive of the Department of Corrections. (2000).

Gladieux, L.E. \& Swaill, W.S. (1999) The Virtual University and Educational Opportunity: Panacea or False Hope? Higher Education Management. 11 (2): 43-56.

Hardie-Boys, N. (1996) Workload and stress: A report of ASTE members. Wellington: New Zealand Council for Educational Research and the Association of Staff in Tertiary Education: 19.

Health and Safety in Employment Act 1992, S19.

Kinman, G. (1998) Pressure Points: A Survey into the Causes and Consequences of Occupational Stress in UK Academic and Related Staff. London: Association of University Teachers.

McConville, G. \& Allport, C. (2000) Unhealthy Places of Learning: Working in Australian Universities. Melbourne: National Tertiary Education Union.

McInnes, C. (2000) Changes in Academic Work Roles. Canberra: DETYA.

Ministry of Education (2000) New Zealand's Tertiary Education Sector: 1999 Profile and Trends. Wellington: Ministry of Education.

O'Neill, A. (1990) Polytechnic Tutor Workload and Labour Market Flexibility. ASTE News. June: 6.

Ovens, J. (1995) Is AIT a Family-friendly Workplace? A Survey of AIT ASTE Branch Members. Unpublished paper.

Philp, N.E. (1993) A Model for the Allocation of Teaching Loads in Academic Departments.
Polytechnic Workloads Working Party (1996) Academic Workload in Polytechnics: The Report of the Workload Working Party. Unpublished report.

\section{Massey University Workloads Advisory Group} (2000) Report of the Workloads Advisory Group to the Vice-Chancellor. Unpublished report.

Riggs, S. (1994) Workloads and Access to Professional Development in a New Zealand Polytechnic. Is Gender a Factor? Unpublished paper.

Sadler, D.R. (2000) Academic Work: Taking Control of Your Time. NTEU Advocate. 7 (4): 18.

Tarling, N. (2000). Professionals and Unionists: A History of the Association of University Staff 1923-98. Wellington: Association of University Staff.

Wergin, J.F. (Ed.) (1994). Analyzing Faculty Workload. San Francisco: Jossey-Bass Publishers.

\section{Appendix I: Principles Underlying Workload} Allocation

\subsection{The workload must be equitable.}

"Equitable" means that staff with comparable responsibilities should have similar workloads. Parttime staff will have workloads that reflect the time they are available for work and that are fair and relative to fulltime staff.

1.2 Total workload should be reasonable.

This means that workload should be manageable within the timelines and deadlines set and that staff are able to maintain a balance between their professional and private lives. It is expected that normal fluctuations will inevitably occur from time to time. However, regularly working more than can reasonably be expected is likely to result in unhealthy levels of stress and reduce effectiveness.

\subsection{Total workload should be safe.}

This means that work will be allocated to minimise physical or mental harm to employees.

\subsection{The allocation of work should be trans} parent and measurable.

The allocation of work should conform to a clear, transparent statement of expectations. The method of quantifying work should be explicit, understandable and defensible. 


\subsection{Workload should be such that it allows the} individual employee to continue to de velop personally.

The allocation of work should enable a career path that facilitates prospects for promotion. Work should be allocated in a way that allows academic staff to maintain credibility in all aspects of academic work. Promotion policies need to reflect the varying balance of academic work so that staff are more willing to share the teaching, administrative and community service demands of the department.

1.6 Individual circumstances should be considered when allocating work.

While the needs of an individual should be balanced within the overall needs of a department, it is recognised that as far as practical the needs of individuals should be recognised. These needs may encompass cultural or community responsibilities, family responsibilities, professional responsibilities and personal preferences. The ILO Maternity Protection Convention 2000 (Article 3) suggests that the specific needs of staff who are pregnant or breastfeeding should be considered in the allocation of work.

\subsection{All aspects of work should be taken into} account when assessing workload.

Tertiary institutions are complex organisations and staff members are involved at different levels in many responsibilities. It is important the total time involved in discharging these responsibilities is considered when determining workload. The balancing of various tasks within a department should take into account that there will be jobs that need to be done but which are universally unpopular. Such jobs should be shared. Work should be allocated to minimise total workload within a department by reducing duplication to a minimum, taking into account the strengths and preferences of individual staff members and eliminating unnecessary tasks.

\subsection{Work should be allocated in such a way that staff retain their professional autonomy}

Academic staff need to retain a large degree of control, personally and as members of a team, over how and when they achieve their work goals.

\section{Appendix II: Processes of Allocating Work}

\subsection{Need for balance}

The process of allocating work should balance the needs of the teaching team, the job satisfaction of

\subsection{Agreement on process}

The process should be agreed by all staff. (The framework for that agreement may be regulated through clauses in the collective agreement or contained in policy, but there may need to be more detailed agreements at team level. These need to be written down and circulated to everyone.)

\subsection{Open process}

Everyone should know what the process is and it should be applied transparently. This may mean that work assignments are available to all members of the team.

\subsection{Advance notice}

Work should be assigned with sufficient notice to allow adequate time for preparation. This implies that work allocation is a planned process, not normally ad hoc.

\subsection{Consistency of application}

The process must be capable of being applied to everyone in an equitable and consistent manner.

\subsection{Participation}

The process should be designed to maximise participation by staff.

\subsection{Right of review}

There should be a mechanism that allows the staff members' work to be reviewed. This should emphasise low-level resolution in the first instance, but should also provide avenues for recourse and support for staff who are not satisfied that their issues have been addressed. Such avenues might include an ombudsman or Workload Review Committee comprising union and management representatives. Ideally such a committee would have institute-wide responsibility to allow comparisons across the institute.

\section{Authors}

\section{Jill Ovens}

Senior Lecturer (Journalism)

Auckland University of Technology and

National President

Association of Staff in Tertiary Education

111 Dixon St

P O Box 27141

Wellington

Jill@aste.ac.nz

Derek McCormack

Deputy Vice-Chancellor for Administration

Auckland University of Technology

Private Bag 92006

Auckland

derek.mccormack@sut.ac.nz 


\begin{tabular}{l}
\hline Agreement or CEC \\
\hline CIT, Christchurch Polytech \\
Institute of Technology, EIT, \\
Northland Polytech, Unitec, \\
Waikato Polytech, Wanganui \\
Polytech, Whitireia Polytech \\
Expire March 12001
\end{tabular}

Hutt Valley Polytech,

Tairawhiti Polytech, , NMIT

Expire March 2001

Taranaki Polytech

Expires March 312001

Bay of Plenty Polytechnic Expires June 12001

Aoraki Polytechnic

Expired September 302000

\section{Features}

All part of a group that negotiated together in 1998 and adopted the following provisions: statement of intent includes commitment to develop detailed workloads policy by February 2000 (most of these include workload bands as described for AUT); workloads policies have included review mechanisms (eg through Contract Monitoring Committee); statement also includes importance of allocating safe, reasonable and equitable workloads, open and clear process, based on sound principles and informed by appropriate quantitative measures; definitions of what is safe, reasonable and equitable; lists factors to be taken into account in allocating workload, including class size, assessment requirements, cultural requirements, participation in research, etc; 825 TTH maximum for academic staff (1000 TTH for tutorial assistants and 660 TTH for those on probation); quarterly limits to ensure spread over year; reduction of TTH for professional development; timetabled teaching no more than 185 days a year; reduction for staff with special responsibilities to be determined by employer but must be equitable and reasonable; weekly duty hours between $8 \mathrm{am}$ and $9.30 \mathrm{pm}$ but no more than 34 hours a week ( 36 by agreement and 37.5 for non-teaching academic staff); no more than 8 hours a week after $5 \mathrm{pm}$ and no more than 2 nights a week except by agreement; weekends only by consent; no more than 8 hours a day except field trips or travel on official business; meal breaks; clinical may be outside $8 \mathrm{am}$ till $5 \mathrm{pm}$; reduction for part-timers in relation to fulltimer; 4 weeks leave exercised at lecturer's discretion (may be used for research leave if degree) plus 5 weeks annual leave and 10 days professional leave.

Regulations as above in contract; commitment for working party to develop workload policies but yet to be developed.

As above but includes annual workload plan process; workload mediation through workload committee including two employer reps and 2 ASTE reps (make recommendations to CEO); Workload Working Party developing detailed model.

Based on annual workload plan prepared by staff member and his/her manager; work parameters are defined (eg available duty days, maximum TTH, individual training needs); negotiation over work plan occurs in November; provides for workload mediation (process unspecified)

Hours of work 37.5 hours; safe, reasonable and equitable workloads with regard to outside-of-work commitments; annual workload 1700 duty hours; annual work plan 47x5-day weeks $=235$ days $(215$ directed duty +20 days discretionary leave); $850 \mathrm{TTH}$; off-campus time spent travelling or involving overnight stay with students (eg noho marae) to be counted as duty; annual workload to be allocated previous December; workload mediation procedures in place; statement of intent to look at degree teaching Additional workloads principles contained in CEC; 835 TTH maximum; probationary lecturers do 0.9 of fulltime load ( 0.8 in "group"); limits on weekly hours, etc same as "group"; Workload Committee includes 2 ASTE reps/2employer reps, hears complaints that departmental review has not satisfactorily resolved; discretionary leave as for "group" Workloads to be safe, reasonable and equitable; limit on weekly duty hours (34 or 36 by agreement); 8 hours a day duty hours; meal breaks, etc; workload review committee to review excessive workloads includes ASTE rep; no discretionary leave.
Open Polytechnic

Expires May 12001 